\title{
A TEMÁTICA AMBIENTAL EM DOCUMENTOS CURRICULARES NACIONAIS DO ENSINO MÉDIO
}

\author{
Diógenes Valdanha Neto* \\ Clarice Sumi Kawasaki*
}

RESUMO: Este artigo relata uma pesquisa que investigou em que medida e extensão a temática ambiental é desenvolvida em documentos curriculares nacionais do Ensino Médio, em continuidade a um estudo anterior que realizou similar investigação, porém em documentos curriculares nacionais do Ensino Fundamental (anos finais). Realizouse uma análise do conteúdo dos documentos curriculares em uma abordagem qualitativa da pesquisa educacional. Nesses documentos, a presença da temática ambiental é muito menor e menos significativa quando comparada aos do Ensino Fundamental; além de prevalecer uma concepção conservacionista/científica, trazendo uma visão reducionista e pouco politizada/crítica da temática ambiental no processo educativo. Distintamente, as novas Diretrizes Curriculares Nacionais para o Ensino Médio avançam na inclusão de uma educação ambiental crítica no currículo nacional da escola básica.

Palavras-chave: Temática ambiental. Educação ambiental. Currículo.

\section{ENVIRONMENTAL THEMATIC IN NATIONAL CURRICULUM DOCUMENTS FOR HIGH SCHOOL}

ABSTRACT: This paper reports a study that investigated in which extension the environmental theme is developed in national curriculum documents for high school; continuing a previous similar research undertaken, nevertheless, in national curriculum documents towards elementary school (final years). Curriculum documents' content analysis was conducted in a qualitative approach of educational research. Within high school curriculum documents, the presence of environmental issues is inferior and less significant when compared to the elementary school, as well as with a predominantly conservationist/scientific approach, bringing a reductionist and less politicized/critical view of environmental issues. Distinctively, the new National Curriculum Guidelines for High School advance in the inclusion of a critical environmental education in the national curriculum for basic school.

Keywords: Environmental thematic. Environmental education. Curriculum.
* Doutorando em Educação pela Faculdade de Educação da Úniversidade de São Paulo (FÉ/USP). Docente do Departamento de Educação em Ciências, Matemática e Tecnologias pertencente ao Instituto de Ciências Exatas, Naturais e Educação da Universidade Federal do Triângulo Mineiro (DECMT/ICENE/UFTM).

E-mail: diogenesvn@yahoo.com.br.

* * Doutora em Educação pela Faculdade de Educação da Universidade de São Paulo (FE/USP). Docente do Departamento de Educacão, Informação e Comunicação da Faculdade de Filosofia, Ciências e Letras da Universidade de São Paulo (DEDIC IFFCLRP USP), Ribeirão Preto, SP E-mail: sumi@ffclrp.usp.br.

DOI - http://dx.doi.org/10.1590/1983-21172015170210 


\section{LA TEMÁTICA AMBIENTAL EN DOCUMENTOS CURRICULARES NACIONALES DE LA EDUCACIÓN SECUNDARIA}

RESUMEN: Este artículo relata una investigación que busca saber en qué medida y extensión la temática ambiental es desarrollada en documentos curriculares nacionales de la Educación Secundaria, en continuidad a un estudio anterior que realizó similar investigación, pero en documentos curriculares nacionales de la Educación Primaria (años finales). Fue realizado un análisis del contenido de los documentos curriculares en un abordaje cualitativo de la investigación educacional. En eses documentos, la temática ambiental es mucho más chica y menos significativa que la comparada a los de Educación Primaria; además de prevalecer una concepción conservacionista/ científica, que trae una visión reduccionista y poco politizada/crítica de la temática ambiental en el proceso educativo. Distintamente, las nuevas Directrices Curriculares Nacionales para la Educación Secundaria avanzan en la inclusión de una educación ambiental crítica en el Currículo Nacional de la Educación Primaria.

Palabras clave: Temática ambiental. Educación Ambiental. Currículum. 


\section{INTRODUCุÃO}

Estudos que versam sobre a inserção da temática ambiental em documentos curriculares, principalmente nas Diretrizes Curriculares Nacionais (DCN) e nos Parâmetros Curriculares Nacionais (PCN), são amplamente desenvolvidos. Todavia, tais estudos realizam, majoritariamente, análises parciais desses documentos curriculares, restringindo-se a uma ou outra disciplina escolar e/ou um ou outro nível de ensino (LEMOS; DAVID, 2011; BUENO; OLIVEIRA, 2009; CUNHA, 2007; FILVOCK; TEIXEIRA, 2006; INVERNIZZI, TOMAZELLO, 2000). A pesquisa mais ampla, a qual este artigo relata apenas uma parte, buscou analisar esses documentos curriculares em sua totalidade, incluindo-se todas as áreas disciplinares e todos os níveis de ensino da educação básica. Até o presente momento, dois desses níveis - fundamental e médio - foram contemplados nesta análise, faltando apenas os documentos da Educação Infantil.

Os documentos curriculares nacionais com caráter mandatório são as DCN, tendo um formato mais reduzido e generalista do que os documentos dos PCN, sendo estes apenas uma "possibilidade" de embasamento e encaminhamento curricular (BONAMINO; MARTÍNEZ, 2002). Tal fato não diminui sua importância no cenário escolar brasileiro, uma vez que foram amplamente divulgados pelos textos didáticos e pelos vários cursos de formação docente que veicularam suas orientações muito mais como determinação curricular do que como "possibilidade".

Foi em 2009 que se iniciou a primeira etapa deste estudo, na qual foram analisados os documentos curriculares do Ensino Fundamental (EF) - Diretrizes Curriculares Nacionais do Ensino Fundamental (BRASIL, 1998a) e Parâmetros Curriculares Nacionais do Ensino Fundamental (BRASIL, 1998b), cujos resultados principais encontram-se em Valdanha Neto e Kawasaki (2013). Concluiu-se nesta etapa que a temática ambiental se faz presente nesses documentos, porém de forma isolada no caderno do Tema Transversal Meio Ambiente, e dispersa em alguns dos demais cadernos - principalmente no de Ciências, Geografia e Artes -, deixando de cumprir, assim, a transversalidade dessa temática proposta nesses documentos. Além disso, identificou-se uma pluralidade de tendências e concepções de Meio Ambiente (MA) e de Educação Ambiental (EA).

Este artigo relata a segunda etapa desta pesquisa mais ampla, analisando os documentos curriculares do Ensino Médio: as Diretrizes Curriculares Nacionais do Ensino Médio (BRASIL, 1998c) e sua recente versão (BRASIL, 2012a), e os Parâmetros Curriculares Nacionais do Ensino Médio (BRASIL, 1999a). Ao final, os resultados desta pesquisa (documentos do Ensino Médio) são apresentados de forma comparativa aos resultados obtidos na etapa anterior (documentos do Ensino Fundamental).

\section{TEMÁTICA AMBIENTAL E PARÂMETROS CURRICULARES ${ }^{1}$}

A origem da Educação Ambiental (EA) no contexto escolar brasileiro encontra-se nas disciplinas específicas da Biologia (TRIVELATO, 2001), Ecologia ou 
Ciências Naturais (KAWASAKI; CARVALHO, 2009), trazendo reflexos à abordagem dada à temática ambiental nos processos educativos e no currículo escolar da educação básica.

O enfoque deste artigo está na abordagem da Temática Ambiental (TA) no que Gimeno Sacristán (2008) denomina de primeiro nível de objetivação do currículo, isto é, o "currículo prescrito":

Em todo sistema educativo, como consequência das regulações inexoráveis às quais está submetido, levando em conta sua significação social, existe algum tipo de prescrição ou orientação do que deve ser seu conteúdo, principalmente em relação à escolaridade obrigatória. São aspectos que atuam como referência na ordenação do sistema curricular, servem de ponto de partida para a elaboração de materiais, controle do sistema, etc. (GIMENO SACRISTÁN, 2008, p. 104)

Em uma revisão bibliográfica acerca de pesquisas que versam sobre a TA em propostas curriculares, verificou-se que estas realizam análises parciais desses documentos, dedicando-se à análise de um dos níveis de ensino (predominantemente no Ensino Fundamental), ou de uma das partes específicas dos documentos - Introdução, Temas Transversais ou Cadernos das áreas disciplinares (LEMOS; DAVID, 2011; BUENO; OLIVEIRA, 2009; CUNHA, 2007; FILVOCK; TEIXEIRA, 2006; INVERNIZZI, TOMAZELLO, 2000).

Rink e Megid Neto (2009), partindo de uma análise dos trabalhos publicados nos anais dos Encontros de Pesquisa em Educação Ambiental (EPEA), de 2001 a 2007, verificam que $77 \%$ dos trabalhos referem-se a investigações no contexto escolar e que apenas 9,6\% destes possuem enfoque no Ensino Médio, indicando uma lacuna nas pesquisas desse nível escolar. Destarte, serão brevemente descritas as publicações preponderantes que compõem a revisão bibliográfica, indicando uma congruência com os dados de Rink e Megid Neto (2009).

O estudo de Lemos e David (2011) apresenta reflexões acerca da presença da TA nos PCN do EF, afirmando que os principais termos que esses documentos se valem para tratar da questão ambiental são meio ambiente, sustentabilidade e diversidade. Além disso, as autoras fazem uma discussão em defesa da presença da EA nas propostas curriculares para o EF, porém indicam a necessidade de elementos políticos como constituintes dessa EA.

Bueno e Oliveira (2009) fazem um estudo "teórico-bibliográfico" do discurso da sustentabilidade presente no caderno dos Temas Transversais "Meio Ambiente e Saúde" (1998), trazendo uma visão histórica do tratamento à questão ambiental e valoriza a presença do discurso da sustentabilidade nos PCN, em contraponto a uma visão que naturaliza a degradação ambiental. Enfatizam a importância da presença da TA nos currículos oficiais à medida que buscam uma melhoria na qualidade de vida nos níveis social, político e econômico.

Investigando a abordagem da TA no caderno de Ciências dos PCN/EF, Cunha (2007) faz uma discussão do papel dos PCN no plano nacional da política educacional e faz uma descrição de como o tema MA aparece no caderno de Ciências, 
trazendo também trechos de citação integral para análise, concluindo que há um reducionismo na abordagem dada à TA, fortemente ancorada em uma visão "cientificista" e "utilitária" de relação com o MA. Afirma que a EA se encontra com indicações difusas, como a execução de simples atividades esporádicas, e que a abordagem encontrada constitui "um grande obstáculo ao desenvolvimento de práticas pedagógicas voltadas à superação da crise ambiental que ora vivenciamos” (CUNHA, 2007, p. 230).

Filvock e Teixeira (2006) analisam as relações ser humano-natureza contidas no caderno dos Temas Transversais "Meio Ambiente e Saúde" (1ª a $4^{\mathrm{a}}$ séries), principalmente a partir de trechos elencando os objetivos e conteúdos da TA. Concluem que esse documento tem sua abordagem centrada nas possibilidades "tecnocráticas", "cientificistas", "comportamentalistas" e "conservadoras" da relação ser humano-natureza, mantendo uma EA que não sustenta a formação de sujeitos críticos.

Invernizzi e Tomazello (2000), ao analisarem o caderno dos Temas Transversais "Meio Ambiente e Saúde", realizam uma pesquisa sobre os processos educativos para a EA presentes nos PCN, tendo em vista a importância destes para a formação de professores. Realizam uma análise de conteúdo desse Caderno, utilizando-se da categorização proposta por Lucas (2000 apud INVERNIZZI; TOMAZELLO, 2000): educação no ambiente, educação sobre o ambiente e educação para o ambiente. Os resultados revelam que, nas frases que indicam as finalidades educacionais relacionadas ao tema transversal MA, a categoria educação para o ambiente é predominante; já nas frases referentes aos conteúdos propostos par o tema transversal MA, a categoria educação sobre o ambiente predomina.

Dessa forma, percebe-se que há uma discussão ainda viva da presença da TA nos documentos curriculares nacionais, porém muito concentrada nos PCN para o EF e em cadernos específicos. Espera-se, assim, que a presente pesquisa contribua para uma análise global da presença da TA nos documentos curriculares nacionais da educação básica.

\section{METODOLOGIA}

Similar ao que foi feito na primeira etapa deste projeto de pesquisa (VALDANHA NETO; KAWASAKI, 2013), a presente investigação situa-se em uma abordagem qualitativa da pesquisa educacional (BOGDAN; BIKLEN, 1994), propondo-se a realizar uma análise de conteúdo (BARDIN, 2009) dos documentos dos Parâmetros Curriculares Nacionais para o Ensino Médio (PCN/EM), os quais possuem 280 páginas (BRASIL, 1999a), das Diretrizes Curriculares Nacionais para o Ensino Médio (DCN/EM) de 1998, com 7 páginas (BRASIL, 1998c), e também de sua versão recentemente publicada, em 2012, com 9 páginas (BRASIL, 2012a). Os documentos dos PCN/EM constituem um caderno único que trata de todas as áreas e disciplinas, contendo as "bases legais" para a criação e o desenvolvimento do documento, e as três grandes áreas nas quais é dividido são: Linguagens, Códigos e suas Tecnologias; Ciências da Natureza, Matemática e suas Tecnologias; e Ciências Humanas e suas Tecnologias. 
A análise desses documentos iniciou-se a partir de uma leitura flutuante, buscando uma visão panorâmica, seguida de uma seleção de Unidades de Registro (UR) que indicam a presença da TA nos processos educativos. Segundo Bardin (2009, p. 130, grifo nosso), "A unidade de registro é a unidade de significação a codificar e corresponde ao segmento de conteúdo a considerar como unidade de base, visando à categorização e à contagem frequencial". As UR selecionadas para esta pesquisa foram: Meio Ambiente (MA), Educação Ambiental (EA), Ambient* (AMB) e Natureza (NAT), escolhidas mediante diversas tentativas de análise e avaliações consecutivas que apontaram essas como sendo as mais reveladoras para captar a presença da TA nesses documentos.

$\mathrm{Na}$ segunda etapa da investigação, os documentos foram lidos na íntegra e analisados em profundidade, procurando identificar as concepções de MA e de EA que não estavam explicitadas, mas que se encontravam, de forma tácita, no encadeamento de ideias sobre essa temática no texto. Para tanto, utilizou-se a Unidade de Contexto (UC), que se refere aos segmentos das mensagens aos quais as Unidades de Registro (UR), anteriormente levantadas, estão inseridas (BARDIN, 2009). Essas UC foram analisadas à luz de referenciais teóricos que oferecem sistematizações para diferentes concepções de MA e EA, encontradas nos autores: Layrargues e Lima (2014), Silva e Campina (2011), Sauvé (2005) e Amaral (2004).

Previamente à exposição dos resultados obtidos e discussões encaminhadas será apresentado um quadro de siglas (Quadro 1) para auxiliar a leitura e compreensão deste artigo, principalmente ao público externo ao campo de pesquisa da EA.

Quadro 1 - Siglas utilizadas no artigo

\begin{tabular}{|c|c|}
\hline Expressão & Sigla \\
\hline Ambient* (Ambiental+Ambiente) & AMB \\
\hline Ciência, Tecnologia e Sociedade & CTS \\
\hline Diretrizes Curriculares Nacionais & DCN \\
\hline Educação Ambiental & EA \\
\hline Ensino Fundamental & EF \\
\hline Ensino Médio & EM \\
\hline Meio Ambiente & MA \\
\hline Natureza & NAT \\
\hline Parâmetros Curriculares Nacionais & PCN \\
\hline Temas Transversais & TT \\
\hline Temática Ambiental & TA \\
\hline Unidade de Contexto & UC \\
\hline Unidade de Registro & UR \\
\hline
\end{tabular}




\section{RESULTADOS E DISCUSSÕES}

Serão expostos e analisados os dados obtidos na investigação, buscando também apresentar trechos dos documentos que ilustram as abordagens da TA e da EA que estão mais próximas de seu conteúdo.

\section{A análise dos documentos curriculares do Ensino Médio}

$\mathrm{Na}$ Tabela 1 verifica-se uma grande disparidade na presença de UR encontradas nesses dois documentos, sendo que os documentos das DCN/EM apresentam uma frequência muito menor em relação aos documentos dos PCN/EM. Certamente, tal fato se explica pela grande diferença no número de páginas desses documentos. Nos documentos das DCN/EM foram identificadas apenas 4 UR, sendo que as UR MA e EA não foram encontradas; a UR AMB foi encontrada uma vez, referindo-se ao ambiente escolar; e a UR NAT foi encontrada três vezes, referindo-se à natureza das manifestações da linguagem, à natureza das tecnologias da informação e à área das "Ciências da Natureza", podendo-se, assim, considerar que a TA é inexistente nesse documento.

Tabela 1 - Número de unidades de registro nos documentos das DCN/EM (1998c) e dos PCN/EM (1999a

\begin{tabular}{|c|l|l|l|l|l|}
\hline Documentos & MA & EA & AMB & NAT & Total \\
\hline DCN/EM (1998) & 0 & 0 & 1 & 3 & 4 \\
\hline PCN/EM (1999) & 4 & 0 & 63 & 96 & 163 \\
\hline Total & 4 & 0 & 64 & 99 & 167 \\
\hline
\end{tabular}

Fonte: Elaborado pelos autores.

A Tabela 2 mostra que das 163 ocorrências de UR presentes nos documentos dos PCN/EM, há uma predominância da UR NAT (96) e da AMB (33), sendo que a UR MA foi encontrada apenas quatro vezes e a UR EA não foi encontrada. Verifica-se ainda uma maior concentração dessas UR na área de Ciências da Natureza, Matemática e suas Tecnologias.

Tabela 2 - Número de unidades de registro nos PCN/EM (1999a), conforme as grandes áreas curriculares presentes nestes documentos

\begin{tabular}{|c|l|l|l|l|l|}
\hline Documentos & MA & EA & AMB & NAT & Total \\
\hline Bases Legais & 0 & 0 & 2 & 5 & 7 \\
\hline Ciências da Natureza, Matemática e suas Tecnologias & 2 & 0 & 47 & 38 & 87 \\
\hline Ciências Humanas e suas Tecnologias & 0 & 0 & 3 & 35 & 38 \\
\hline Linguagens, Códigos e suas Tecnologias & 2 & 0 & 11 & 18 & 31 \\
\hline Total & 4 & 0 & 33 & 96 & 163 \\
\hline
\end{tabular}




\section{Ciências da Natureza, Matemática e suas Tecnologias}

A área de Ciências da Natureza, Matemática e suas Tecnologias é, dentre as grandes áreas curriculares, a que apresenta o maior número de UR, 87 (53\%), sendo que é a parte introdutória do texto dessa grande área (28 ocorrências) e a disciplina de Biologia (29 ocorrências) que concentram a maior parte dessas UR. As demais disciplinas contidas apresentam as seguintes ocorrências de UR: Química (17), Física (7) e Matemática (6).

Com a realização de uma leitura mais detalhada e aprofundada de todos os documentos, verificou-se que, na área de Ciências da Natureza, Matemática e suas Tecnologias, há uma orientação para que o tema socioambiental seja abordado pelas diferentes áreas disciplinares, conforme o trecho abaixo:

A poluição ambiental, por sua vez, seja ela urbana ou rural, do solo, das águas ou do ar, não é algo só "biológico", só "físico" ou só "químico", pois o ambiente, poluído ou não, não cabe nas fronteiras de qualquer disciplina, exigindo, aliás, não somente as Ciências da Natureza, mas também as Ciências Humanas, se se pretender que a problemática efetivamente socioambiental possa ser mais adequadamente equacionada, num exemplo da interdisciplinaridade imposta pela temática real. (BRASIL, 1999a, p. 209)

Por meio de uma abordagem inter/transdisciplinar e partindo-se de conteúdos clássicos da área específica como a poluição ambiental, é proposta a discussão de aspectos que vão além das fronteiras disciplinares:

Assim, a consciência desse caráter interdisciplinar ou transdisciplinar, numa visão sistêmica, sem cancelar o caráter necessariamente disciplinar do conhecimento científico mas completando-o, estimula a percepção da inter-relação entre os fenômenos, essencial para boa parte das tecnologias, para a compreensão da problemática ambiental e para o desenvolvimento de uma visão articulada do ser humano em seu meio natural, como construtor e transformador deste meio. Por isso tudo, o aprendizado deve ser planejado desde uma perspectiva a um só tempo multidisciplinar e interdisciplinar, ou seja, os assuntos devem ser propostos e tratados desde uma compreensão global, articulando as competências que serão desenvolvidas em cada disciplina e no conjunto de disciplinas, em cada área e no conjunto das áreas. (BRASIL, 1999a, p. 209-211)

A TA está presente também por meio de uma abordagem da relação Ciência, Tecnologia e Sociedade (CTS), permeando a proposta da área:

Esses conhecimentos exigem, entre outras, competências e habilidades de reconhecer o papel da Química no sistema produtivo, reconhecer as relações entre desenvolvimento científico e tecnológico e aspectos sociopolítico-econômicos, como nas relações entre produção de fertilizantes, produtividade agrícola e poluição ambiental, e de reconhecer limites éticos e morais envolvidos no desenvolvimento da Química e da tecnologia, apontando a importância do emprego de processos industriais ambientalmente limpos, controle e monitoramento da poluição, divulgação pública de índices de qualidade ambiental. (BRASIL, 1999a, p. 245) 
Sendo assim, pode-se observar que a TA é desenvolvida por meio da convivência de diversas abordagens da EA presentes nesse documento, tais como: conservacionista (LAYRARGUES; LIMA, 2014; SILVA; CAMPINA, 2011; SAUVÉ, 2005), resolutiva, cientifica e sistêmica (SAUVÉ, 2005) e, em certa medida, uma corrente de pensamento crítico (LAYRARGUES; LIMA, 2014; SILVA; CAMPINA, 2011; SAUVÉ, 2005; AMARAL, 2004). As incursões por uma abordagem mais crítica da TA são ainda muito tímidas devido à falta de aspectos sociais e políticos nas orientações relativas à TA.

Dessa forma, é possível observar que o conteúdo dessa grande área não se limita a uma compreensão fragmentada da natureza (corrente naturalista), uma vez que a abordagem que mais se destaca é a científica que, conforme explica Sauvé (2005), é uma corrente que se direciona na identificação dos diversos fatores relacionados a questões ambientais - possuindo uma abordagem miscigenada entre a resolução de problemas (corrente resolutiva) e uma visão sistêmica (corrente sistêmica) do MA. Esse dado é convergente com as considerações de Cunha (2007) acerca das abordagens da TA no caderno de Ciências Naturais dos PCN/EF.

Todavia, reflexões de cunho sociopolítico permeiam de maneira pouco incisiva esse caderno. Quanto à presença significativa de UR na parte introdutória desse documento e em trechos isolados do texto, verifica-se que nestes a TA aparece de forma difusa, sem expressar claramente quais são as concepções de MA e de EA veiculadas.

\section{Ciências Humanas e suas Tecnologias}

Esta grande área apresenta 38 ocorrências (23\%) de UR, distribuindo-se nas disciplinas que a compõem: História (10), Geografia (10), Filosofia (6), Ciências Sociais (2) e texto introdutório (10).

Semelhante à área de Ciências da Natureza, Matemática e suas Tecnologias, a área de Ciências Humanas e suas Tecnologias propõe uma abordagem interdisciplinar da TA, conforme o trecho que se segue:

\footnotetext{
Nesse sentido, a Geografia pode articular-se de forma interdisciplinar com a Economia e a História, quando tratar das questões ligadas aos processos de formação da divisão internacional do trabalho e a formação dos blocos econômicos. Questões contemporâneas, tais como crise econômica, globalização do sistema financeiro, poder do Estado e sua relação com a economia e as novas resultantes espaciais das desigualdades sociais, podem ser tratadas pela Geografia em diálogo com a Economia e a Sociologia. A espacialização dos problemas ambientais e da biotecnologia favorece a interação com a Biologia, a Física, a Química, a Filosofia e, mais uma vez, a Economia. (BRASIL, 1999a, p. 312)
}

Mantém, ainda, indicativos do trabalho educacional por meio de uma abordagem CTS:

A revolução técnico-científica não dá receitas prontas e traz no seu interior uma velocidade de transformações ante as quais é inútil a simples análise da aparência. Nesta visão, como afirmou Soja, fica claro que é impossível continuar olhando o planeta apenas a partir de "sua primeira natureza, ou seja: seu contexto ingenuamente dado, pois uma segunda natureza se apresenta e 
esta não abandonou os aspectos visíveis do objeto, mas incorporou o resultado da ação e relação social". Ao buscar compreender as relações econômicas, políticas, sociais e suas práticas nas escalas local, regional, nacional e global, a Geografia se concentra e contribui, na realidade, para pensar o espaço enquanto uma totalidade na qual se passam todas as relações cotidianas e se estabelecem as redes sociais nas referidas escalas. (BRASIL, 1999a, p. 310)

Pode-se observar que nos trechos referidos há um esforço no sentido de atribuir à TA um tratamento interdisciplinar, porém tais premissas não aparecem nos encaminhamentos pedagógicos e didáticos ao longo desse documento, demonstrando ter um caráter mais normativo do que prático.

Sendo assim, é possível notar que a TA é desenvolvida por meio da convivência de diversas abordagens da EA presentes nesse documento, tais como: sistêmica e científica (SAUVÉ, 2005), na busca pela totalidade das relações entre os fatores que exercem forças sobre as questões ambientais e na aposta na biotecnologia como integradora de esferas políticas e científicas, além da conservacionista (LAYRARGUES; LIMA, 2014; SILVA; CAMPINA, 2011; SAUVÉ, 2005) e do desenvolvimento sustentável e sustentabilidade (SAUVÉ, 2005; AMARAL, 2004), buscando em um pano de fundo a manutenção de um determinado estado de conservação do meio natural. É perceptível que o texto é orientado na direção de um discurso que enfatiza a importância do pensamento crítico, todavia, mais uma vez faltam encaminhamentos pedagógicos e didáticos nessa direção.

\section{Linguagens, Códigos e suas Tecnologias}

Esta área é a que possui menos ocorrências de UR, sendo apenas 31 (20\%) ocorrências do total, distribuindo-se nas disciplinas: Arte (10), Língua Portuguesa (6), Educação Física (3), Língua Estrangeira Moderna (1) e Informática (1); e o texto introdutório (10).

Há duas menções à UR MA, sendo que ambas são utilizadas associadas ao conceito de "ecologia acústica". Uma das ocorrências aparece em nota de rodapé na definição do conceito citado: "Ecologia Acústica: é o estudo das relações entre o organismo vivo e o meio ambiente [...]” (BRASIL, 1999a, p. 177). A outra consta no texto da mesma página, que se segue:

Utilizar conhecimentos de "ecologia acústica", enfocando diversos meios ambientes na análise, apreciação, reflexão e posicionamento frente a causas e consequências de variadas "paisagens sonoras", projetando transformações desejáveis e de qualidade para o coletivo das pessoas. (BRASIL, 1999a, p. 177)

Embora essa diretriz seja bastante produtiva, ao se pensar nas diferentes abordagens que se pode dar à TA, em todo o documento esse é o único parágrafo que faz menção a essa abordagem, trazendo as definições de "ecologia acústica" e "paisagem sonora" apenas em nota de rodapé, o que não encoraja uma apropriação de tal proposta. Além disso, reitera-se o fato de que a disciplina de Arte é a única que apresenta alguma consideração explícita sobre a TA. 
Considera-se que as correntes de EA presentes nesse documento estão relacionadas, principalmente, às abordagens: resolutiva (SAUVÉ, 2005) e pragmática (LAYRARGUES; LIMA, 2014; SILVA; CAMPINA, 2011). A Ecologia Acústica parece ter o potencial para ser desenvolvida de modo a se caracterizar como uma abordagem mais crítica da EA, porém do modo como está apresentada, superficialmente e enfatizando a resolução de problemas, observa-se uma abordagem predominantemente resolutiva e pragmática. Ainda, enfatiza-se que há uma grande perda em qualidade do tratamento dado à TA na disciplina de Arte quando comparado ao caderno dos PCN de Ensino Fundamental (BRASIL, 1998b), o qual traz a TA de maneira mais integrada aos objetivos da disciplina e às metodologias de ensino (VALDANHA NETO; KAWASAKI, 2013).

\section{As novas Diretrizes Curriculares Nacionais para o Ensino Médio}

Este documento revelou considerável mudança na presença da TA, conforme demonstra a Tabela 3, que traz uma comparação entre as duas versões das $\mathrm{DCN} / \mathrm{EM}$ :

Tabela 3 - Unidades de registro nas Diretrizes Curriculares Nacionais para o Ensino Médio publicadas em 1998 e em 2012

\begin{tabular}{|c|l|l|l|l|l|}
\hline Documentos & MA & EA & AMB & NAT & Total \\
\hline DCN/EM (1998) & 0 & 0 & 1 & 3 & 4 \\
\hline DCN/EM (2012) & 1 & 3 & 10 & 5 & 19 \\
\hline Total & 4 & 0 & 64 & 99 & 167 \\
\hline
\end{tabular}

Fonte: Elaborado pelos autores.

A leitura desse documento confirma uma maior atenção dada à TA, principalmente no inciso IV e parágrafo único $1^{\circ}$ do Artigo $5^{\circ}$, e também no Artigo 16, incisos I e XVII, que seguem transcritos na íntegra:

Art. $5^{\circ} \mathrm{O}$ Ensino Médio em todas as suas formas de oferta e organização, baseia-se em: [...]

IV - sustentabilidade ambiental como meta universal;

$[\cdots]$

$\int 1^{\circ} \mathrm{O}$ trabalho é conceituado na sua perspectiva ontológica de transformação da natureza, como realização inerente ao ser humano e como mediação no processo de produção da sua existência. (BRASIL, 2012a)

Art. 16. O projeto político-pedagógico das unidades escolares que ofertam o Ensino Médio deve considerar:

I - atividades integradoras artístico-culturais, tecnológicas e de iniciação científica, vinculadas ao trabalho, ao meio ambiente e à prática social.

$[\cdots]$

XVII - estudo e desenvolvimento de atividades socioambientais, conduzindo a Educação Ambiental como uma prática educativa integrada, contínua e permanente. (BRASIL, 2012a) 
A presença de uma compreensão marxiana de "trabalho" é importante para o desenvolvimento da TA, pois, conforme o trecho do $\int 1^{\circ}$ do Artigo $5^{\circ}$, o trabalho relaciona-se com a transformação da natureza. Assim, configura-se como uma compreensão valiosa para a EA crítica, focalizando no controle dos processos de produção a sua luta política, uma vez que a busca desenfreada pelo acúmulo de capital tem consequências nefastas ao MA. Além disso, esse documento apresenta referências à Política Nacional de Educação Ambiental (PNEA) (BRASIL, 1999b), o que indica uma tentativa mais consistente de um tratamento integrado das políticas públicas curriculares com as políticas públicas de EA.

A consideração do tema MA e o desenvolvimento de atividades socioambientais, conduzindo ao desenvolvimento da EA como uma prática educativa integrada, contínua e permanente no projeto político-pedagógico das unidades escolares do ensino médio (Artigo 16, inciso XVII), bem como a postulação do significado da EA na condição de prática social, explicitado em um documento com poucas páginas, demonstram um avanço em relação à versão anterior das DCN/EM (1998a), no que se refere à abordagem dada à TA no currículo prescrito. Verifica-se que as novas DCN/ EM (BRASIL, 2012a) progridem no tratamento dado à TA em relação ao documento das DCN/EM anterior (BRASIL, 1998c).

Por fim, destaca-se que os trechos desse documento podem ser relacionados às seguintes abordagens da EA: da sustentabilidade (SAUVÉ, 2005) e do pensamento crítico (LAYRARGUES; LIMA, 2014; SILVA; CAMPINA, 2011; SAUVÉ, 2005; AMARAL, 2004).

\section{Uma perspectiva comparativa da presença da TA nos documentos curriculares do Ensino Fundamental e do Ensino Médio}

Comparando os resultados obtidos na primeira etapa da pesquisa (documentos curriculares do Ensino Fundamental) com os obtidos no presente estudo (documentos curriculares do Ensino Médio), pode-se observar algumas convergências e divergências, conforme a Tabela 4 abaixo.

Com relação à presença da TA nos documentos dos PCN/EF (BRASIL, 1998b) e dos PCN/EM (BRASIL, 1999a), observa-se uma ocorrência muito maior de UR nos documentos do EF (1486 ocorrências) em relação aos do Ensino Médio (163), sendo que no EF há 203 ocorrências da UR MA e 40 ocorrências da UR EA, e no Ensino Médio há apenas quatro ocorrências de UR MA e nenhuma de EA. Já em relação à UR NAT, os documentos dos PCN/EM apresentam um número maior de ocorrências de UR. Mesmo com a discrepância de páginas entre os documentos, uma vez que o PCN/EF possui com a somatória de seus cadernos (todos analisados) 1626 páginas, e o PCN/EM com seu caderno único possui 280 páginas, a presença da TA é destacadamente mais forte no documento para o EF.

Verifica-se que as DCN/EF, que possuem apenas duas páginas, trazem também apenas duas ocorrências de UR, e pode-se afirmar que a TA é muito incipiente nesse documento, bem como nas DCN/EM que, com sete páginas, contém apenas quatro das UR selecionadas. 
Tabela 4 - Unidades de registro em uma perspectiva comparativa entre todos os documentos analisados nesta investigação, incluindo as DCN/EF (1998a) e os PCN/EF (1998b) - com elaboração parcialmente pautada no trabalho de Valdanha Neto e Kawasaki (2013)

\begin{tabular}{|l|l|l|l|l|l|}
\hline UR & DCN/EF & PCN/EF & DCN/EM & PCN/EM & DCN/EM (2012) \\
\hline MA & 1 & 203 & 0 & 4 & 1 \\
\hline EA & 0 & 40 & 0 & 0 & 3 \\
\hline AMB & 1 & 702 & 1 & 33 & 10 \\
\hline NAT & 0 & 541 & 3 & 96 & 5 \\
\hline Total & 2 & 1486 & 4 & 163 & 19 \\
\hline
\end{tabular}

Fonte: Elaborado pelos autores.

Como é possível verificar, evidenciou-se uma pobre presença da TA nos documentos dos PCN/EM (BRASIL, 1999a) e das DCN/EM (BRASIL, 1998c), como indicam as tabelas 1 e 3. Entretanto, foi positivo ter encontrado nas novas DCN/EM (BRASIL, 2012a, uma presença mais significativa e crítica da TA. Além de constatar, no próprio texto desses documentos, uma convergência entre as políticas públicas nacionais curriculares e as políticas públicas em EA, como a PNEA.

Com relação às abordagens dadas à TA nas propostas para Ensino Fundamental (BRASIL, 1998b; BRASIL, 1998a) e Médio (BRASIL 1998c; BRASIL, 1999a), observa-se que as primeiras são mais exitosas em trazer aspectos da EA crítica (LAYRARGUES; LIMA, 2014; SILVA; CAMPINA, 2011; SAUVÉ, 2005; AMARAL, 2004) para o currículo prescrito, apresentando possibilidades concretas para uma abordagem socioambiental das práticas educativas em EA. Nos documentos para o Ensino Médio (BRASIL 1998c; BRASIL, 1999a) predominam os aspectos mais conservadores e pragmáticos (LAYRARGUES; LIMA, 2014; SILVA; CAMPINA, 2011), naturalistas (SAUVÉ, 2005) e condizentes com o que Amaral (2004) classifica como tendência do "adestramento ambiental". Já nos documentos novos das DCN/EM (BRASIL, 2012a), observa-se mais claramente a vertente crítica da EA.

\section{CONSIDERACִÕES FINAIS}

A TA permeia as propostas de currículo prescrito nacionais desde o $\mathrm{EF}$, em que se encontra explicitamente apresentada como um tema transversal dos PCN/EF (BRASIL, 1998b). Todavia, essa diretriz situa-se apenas no caderno do Tema Transversal "Meio Ambiente" e, de forma dispersa em alguns cadernos, destacadamente em Ciências Naturais, Geografia e Artes (VALDANHA NETO; KAWASAKI, 2013), não se apresentando de forma articulada e, tampouco, permeando a totalidade das diferentes áreas disciplinares que compõem este currículo.

Por sua vez, os documentos curriculares nacionais do EM, com exceção das novas DCN/EM (BRASIL, 2012a), nem sequer apresentam a TA e a EA como temas possíveis e passíveis de serem abordados no currículo escolar, aparecendo de forma in- 
cipiente e difusa nas diferentes partes desses documentos, deixando de cumprir o que está posto na PNEA (BRASIL, 1999b), que afirma que essas temáticas devem estar presentes nos currículos escolares de todos os níveis de ensino e de forma interdisciplinar.

As disciplinas de Ciências Naturais e de Geografia (embora, nos PCN/ EF, a disciplina de Artes também apresente uma presença significativa dessas temáticas) como as principais vias de entrada da TA no currículo escolar do EF já foram apontadas anteriormente por Kawasaki e Carvalho (2009) e Trivelato (2001), bem como por autores de outros países, como Steele (2011) e Hale (1989), que revelam essa mesma tendência nos currículos escolares de suas respectivas localidades. O mesmo se pode dizer em relação ao currículo escolar do EM, já que, nos documentos dos PCN/EM (BRASIL, 1999a), a TA se encontra predominantemente na área curricular de Ciências da Natureza, Matemática e suas tecnologias, sobretudo na disciplina de Biologia; e, também, em menor escala, na disciplina de Geografia, da área curricular de Ciências Humanas e suas Tecnologias. Não obstante, a recorrência dessas disciplinas como as vias introdutórias da TA no currículo escolar deve ser superada para que essas temáticas possam, de fato, permear todas as disciplinas e, finalmente, transversalizar o currículo.

A EA enfrenta nas configurações curriculares desafios basais, sobretudo à conformação disciplinar hegemônica que muitas vezes dificulta a implementação de práticas interdisciplinares por professores (METZ et al., 2010). Todavia, sua crescente presença nas propostas curriculares é importante para que a temática esteja cada vez mais presente na sociedade, mesmo atentos para o fato de que os objetivos da EA, como o de uma formação mais sistêmica e crítica para a compreensão das questões socioambientais, não podem ser garantidos apenas por propostas do currículo prescrito (GONZÁLEZ-GAUDIANO, 2007).

Importante salientar que nos documentos curriculares tanto do EF quanto do EM há uma pluralidade de ideias e concepções que refletem o campo científico e prático da EA, sendo que qualquer busca por uma padronização e/ou homogeneização da abordagem dada à TA pode empobrecer a área. É salutar a multiplicidade de olhares para a TA nos processos educativos, já que conhecê-los e distingui-los torna-se relevante considerando que trazem diferentes perspectivas quanto às suas visões de mundo, meio ambiente, relação sociedade-natureza e educação. A despeito dessas várias possibilidades de abordagem da EA, é essencial situar as discussões relativas à TA em um contexto socioambiental mais amplo, a partir de perspectivas críticas da educação.

Em termos de políticas públicas curriculares, o fato de os documentos dos PCN/EF serem publicados em 1998, enquanto que os do Ensino Médio o foram em 1999, no mesmo ano da publicação da PNEA (BRASIL, 1999b), demonstra uma falta de sintonia e articulação entre as políticas públicas curriculares e as de EA, uma vez que os PCN não conseguem articular a TA e a EA de modo interdisciplinar, conforme propõe a PNEA (BRASIL, 1999b), nem como Tema Transversal, conforme proposto nos PCN/EF. 
Castro, Spazziani e Santos (2012, p. 175) apontam para a necessidade de um diálogo sério entre os diversos atores envolvidos na educação (alunos, pais, secretarias, sindicatos, governos) com vistas a sanar problemas na área de educação, sobretudo da EA. Aqui é considerada, ainda, a necessidade real do diálogo entre as políticas públicas, inclusive nas suas elaborações. Pensando no campo da EA, isso deveria ocorrer de modo a haver maior sintonia entre as políticas públicas educacionais gerais e as de EA, permitindo que as diretrizes continuem avançando.

Em 2012 foram publicadas as Diretrizes Curriculares Nacionais específicas para a Educação Ambiental (BRASIL, 2012b), sendo que, em seu Artigo 2º elas trazem uma definição da EA que inclui tanto a abordagem naturalística (relação ser humano-natureza), como também a esfera social desta (relação ser humano-ser humano), assumindo a EA como prática educativa (trans)formadora das esferas do natural e do social. Estas vêm ao encontro das novas DCN/EM (BRASIL, 2012a), que abrem uma porta em direção ao fortalecimento da abordagem crítica da EA nos processos educativos escolares. Assim, espera-se que, a partir dessas diretrizes legais, seja fortalecida uma (re)ação em cadeia que contribua para o avanço do tratamento dado à TA nos processos educativos, buscando o desenvolvimento dessa abordagem em outros documentos curriculares e materiais didáticos, como os livros didáticos, os quais devem ser elaborados em sintonia com essa perspectiva.

E, finalmente, como discute Steele (2011), considera-se que o encontro entre áreas disciplinares com a EA não se dará de forma passiva, já que este envolve mudanças epistemológicas e práticas decorrentes. Transformações essas que estão em curso, sendo o acompanhamento do processo, em várias esferas, valioso para sua construção social e científica.

\section{NOTAS}

${ }^{1}$ Neste artigo as referências aos PCN do Ensino Fundamental são relativas aos documentos destinados às séries finais - na época da publicação, de $5^{\mathrm{a}}$ a $8^{\mathrm{a}}$ séries.

\section{REFERÊNCIAS}

AMARAL, I. A. Programas e ações de formação docente em educação ambiental. In: TAGLIEBER, J. E.; GUERRA, A. F. S. (Org.). Pesquisa em educação ambiental: pensamentos e reflexões de pesquisadores em educação ambiental. Pelotas: Universitária/ Ed. UFPel, 2004.

BARDIN, L. Análise de conteúdo. 5. ed. rev. e ampl. Lisboa: Ed. 70, 2009.

BOGDAN, R. C.; BIKLEN, S. K. Investigação qualitativa em educação: uma introdução à teoria e aos métodos. Porto: Porto Editora, 1994.

BONAMINO, A.; MARTÍNEZ, S. A. Diretrizes e Parâmetros Curriculares Nacionais para o Ensino Fundamental: a participação das instâncias políticas do Estado. Educação \& Sociedade, Campinas, v. 23, n. 80, p. 368-385, set. 2002. 
BRASIL. Ministério da Educação e do Desporto. Conselho Nacional de Educação. Câmara da Educação Básica. Resolução n. 2, de 7 de abril de 1998. Institui as Diretrizes Curriculares Nacionais para o Ensino Fundamental. Diário Oficial da União, Brasília, DF, 15 abr. 1998a.

BRASIL. Ministério da Educação e do Desporto. Secretaria de Educação Fundamental. Parâmetros curriculares nacionais terceiro e quarto ciclos do ensino fundamental: todos os cadernos, Brasilia, DF, 1998 b.

BRASIL. Ministério da Educação e do Desporto. Conselho Nacional de Educação. Câmara da Educação Básica. Resolução n. 3, de 26 de junho de 1998. Institui as Diretrizes Curriculares Nacionais para o Ensino Médio. Diário Oficial da União, Brasília, DF, 5 ago. 1998c.

BRASIL. Ministério da Educação e do Desporto. Secretaria de Educação Média e Tecnológica. Parâmetros curriculares nacionais do ensino médio, Brasília, DF, 1999a.

BRASIL. Lei no 9.795, de 27 de abril de 1999. Dispõe sobre a educação ambiental, institui a Política Nacional de Educação Ambiental e dá outras providências, Diário Oficial da União, Brasília, DF, 27 abr. 1999b.

BRASIL. Ministério da Educação e do Desporto. Conselho Nacional de Educação. Câmara da Educação Básica. Resolução n. 2, de 30 de janeiro de 2012. Define Diretrizes Curriculares Nacionais para o Ensino Médio. Diário Oficial da União, Brasília, DF, 5 ago. 2012a.

BRASIL. Ministério da Educação e do Desporto. Conselho Nacional de Educação. Resolução n. 2, de 15 de junho de 2012. Institui as Diretrizes Curriculares Nacionais para a Educação Ambiental. Diário Oficial da União, Brasilia, DF, 18 jun. 2012 b.

BUENO, A. C.; OLIVEIRA, E. M. Os Parâmetros Curriculares Nacionais e a problemática ambiental. Travessias, Cascavel, v. 3, n. 1, 2009.

CASTRO, R. S.; SPAZZIANI, M. L.; SANTOS, E. P. Universidade, meio ambiente e parâmetros curriculares nacionais. In: LOUREIRO, C. F.; LAYRARGUES, P. P.; CASTRO, R. S. Sociedade e meio ambiente: a educação ambiental em debate. 7. ed. São Paulo: Cortez, 2012.

CUNHA, M. M. S. A temática ambiental na educação científica segundo as políticas curriculares oficiais brasileiras. Linhas Críticas, Brasília, v. 13, n. 25, p. 219-234, jul./ dez. 2007.

FILVOCK, S. S.; TEIXEIRA, C. F. Análise da relação homem-natureza nos Parâmetros Curriculares Nacionais - temas transversais: educação ambiental. In. VI EDUCERE - CONGRESSO NACIONAL DE EDUCAÇÃO, Anais... Curitiba, 2006.

GONZÁLEZ-GAUDIANO, E. Schooling and environment in Latin America in the third millennium. Environmental Education Research, v. 13, n. 2, p. 155-169, abr. 2007.

GIMENO SACRISTÁN, J. O currículo: uma reflexão sobre a prática. 3. ed. Porto Alegre: Artmed, 2008.

HALE, M. Environmental education in the national curriculum. Journal of Biological Education, v. 23, n. 4, p. 257-259, set. 1989.

INVERNIZZI, M. C. C.; TOMAZELLO, M G. C. Educação ambiental e o espaço de intervenção dos professores segundo os Parâmetros Curriculares Nacionais. In: REUNIÃO ANUAL DA ASSOCIAÇÃO NACIONAL DE PÓS-GRADUAÇÃO 
E PESQUISA EM EDUCAÇÃO, 23., 2000, Caxambu. Anais... Caxambu: ANPED, 2000.

KAWASAKI, C. S.; CARVALHO, L. M. Tendências da pesquisa em educação ambiental. Educação em Revista, Belo Horizonte, v. 25, n. 3, p. 143-147, dez. 2009.

LAYRARGUES, P. P.; LIMA, G. F. C. As macrotendências político-pedagógicas da educação ambiental brasileira. Ambiente \& Sociedade, São Paulo, v. 17, n. 1, mar. 2014.

LEMOS, E. M.; DAVID, C. M. Reflexões sobre o tema transversal meio ambiente no ensino fundamental. Camine: caminhos da educação, Franca, v. 3, n.1, jul. 2011.

LUCAS, A. M. The role of science education in education for the environment. Journal of Environmental Education. v. 12, n. 2, p. 32-37, 1980-81 apud INVERNIZZI, M. C. C.; TOMAZELLO, M. G. C. Educação ambiental e o espaço de intervenção dos professores segundo os Parâmetros Curriculares Nacionais. In: REUNIÃO ANUAL DA ASSOCIAÇÃO NACIONAL DE PÓS-GRADUAÇÃO E PESQUISA EM EDUCAÇÃO, 23., 2000, Caxambu. Anais... Caxambu: ANPED, 2000.

METZ, D.; McMILLAN, B.; MAXWELL, M.; TETRAULT, A. Securing the place of educating for sustainable development within existing curriculum frameworks: a reflective analysis. Canadian Journal of Environmental Education, v. 15, p. 150-169, 2010.

RINK, J.; MEGID NETO, J. Tendências dos artigos apresentados nos encontros de pesquisa em educação ambiental (EPEA). Educação em Revista, Belo Horizonte, v. 25, n. 3, p. 235-263, dez. 2009.

SAUVÉ, L. Uma cartografia das correntes em educação ambiental. In: SATO, M.; CARVALHO, I. C. M. (Org.). Educação ambiental: pesquisa e desafios. Porto Alegre: Artmed, 2005.

SILVA, R. L. F.; CAMPINA, N. N. Concepções de educação ambiental na mídia e em práticas escolares: contribuições de uma tipologia. Pesquisa em Educação Ambiental, Ribeirão Preto, v. 6, n. 1, p. 29-46, 2011.

STEELE, A. Beyond contradiction: exploring the work of secondary science teachers as they embed environmental education in curricula. International Journal of Environmental \& Science Education, v. 6, n. 1, p. 1-22, 2011.

TRIVELATO, S. L. F. O currículo de ciências e a pesquisa em educação ambiental. Educação Teoria e Prática, Rio Claro, v. 9, n. 16/17, p. 57-61, 2001.

VALDANHA NETO, D.; KAWASAKI, C. S. "Meio Ambiente” é um tema transversal nos documentos curriculares nacionais do ensino fundamental? Camine: caminhos da educação, Franca, v. 5, n.1, jul. 2013.

Data de recebimento: 14/12/2014

Data Aprovação: 10/06/2015

Contato:

Diógenes Valdanha Neto

E-mail: diogenesvn@yahoo.com.br

Universidade Federal do Triângulo Mineiro, Instituto de Ciências Naturais, Exatas e Educação (ICENE).

Avenida Doutor Randolfo Borges Júnior, 1400

Uberaba, MG - Brasil

CEP: $38064-200$ 